\title{
DIOSCIN IMPROVES SURVIVAL IN MURINE ENDOTOXEMIA INDUCED BY LIPOPOLYSACCHARIDE
}

\author{
BING HAN ${ }^{3}$, SIYU TAO ${ }^{2, *}$, MEITONG LIU ${ }^{1}$, ZHE FENG $^{1}$ and SHUANG GUAN ${ }^{1, *}$ \\ ${ }^{1}$ College of Food Science and Engneering, Jilin University, Changchun, \\ People's Republic of China \\ ${ }^{2}$ College of Basic Medical Science, Jilin University, Changchun, \\ People's Republic of China \\ ${ }^{3}$ Affiliated Hospital of Changchun University of Traditional Chinese Medicine, \\ Changchun, People's Republic of China
}

\begin{abstract}
Dioscin is a natural steroidal saponin mainly extracted from Dioscoreae rhizoma, which usually used as traditional medicine in East Asia area. Dioscin has various pharmacological actions. However, little is known concerning the role on Lipopolysaccharide (LPS)-induced endotoxemia. The aim of the present study was to investigate the effects and possible mechanisms of dioscin against LPS-induced endotoxemia in mice. The data showed dioscin significantly increased mouse survival when mice were treated with dioscin prior to or after LPS challenge and significantly attenuated TNF- $\alpha$, IL-1 $\beta$ and IL- 6 production in serum. Further studies revealed that dioscin could downregulate LPS-induced nuclear transcription factor $-\kappa B(\mathrm{NF}-\kappa \mathrm{B})$ signal transduction pathways. These observations indicated that dioscin modulated early cytokine responses by blocking $\mathrm{NF}-\mathrm{\kappa B}$ activation, and thus, increased mouse survival in murine endotoxemia induced by LPS.
\end{abstract}

Keywords: dioscin, cytokines, endotoxemia, survival, NF- $\kappa \mathrm{B}$

Endotoxemia is one of the most serious complications of clinically critical patients with high morbidity and mortality worldwide. The major factor is exposure to LPS and other bacterial components (1, 2 ). In the condition of endotoxemia, LPS endotoxin, derived from the outer membranes of Gram-negative bacteria, induces effective cells to release massive pro-inflammatory cytokines (3). The excessive inflammatory cytokines damage the structure and function of vital organs such as lung and even lead to multiple organ dysfunction syndromes (MODS) and death (4). Therefore, how to inhibit the release of pro-inflammatory cytokines and balance immune response has been suggested as an important strategy to improves mortality rate of LPS-endotoxemia.

Dioscoreae rhizoma $(D R)$ has been widely used in food and herbal medicine for a long time in East Asia. DR extract was approved by the Korean Food and Drug Administration (KFDA) in 2011. The KFDA claimed that the extract at a dose of 900 $\mathrm{mg}$ /day effectively regulated the blood sugar level (5). Dioscin, as shown in Figure 1, is a natural steroidal saponin mainly extracted from Dioscoreae rhizoma and has been reported to have various pharmacological actions, such as anti-tumor, anti-hyperlipidemic, anti-fungal, anti-inflammation, protective effect against liver injury (6-9). However, little is known concerning the role of it on LPS-induced endotoxemia. Thus, the aim of the present study was to investigate the effects and possible mechanisms of dioscin against LPS-induced endotoxemia in mice.

\section{EXPERIMENTAL}

\section{Materials}

Dioscin (purity $>98 \%$ ) was ordered from the National Institute for the Control of Pharmaceutical and Biological Products (China). Dimethyl sulfoxide (DMSO), LPS (Escherichia coli 055 : B5), 3(4,5-dimethylthiazol-2-y1)-2,5-diphenyltetrazolium bromide (MTT), and Griess reagent were purchased from Sigma Chemical Co. (St. Louis, MO, USA). TNF- $\alpha$, IL-6, and IL- $1 \beta$ ELISA kits were purchased from Biolegend. Dulbecco's modified Eagle's medium (DMEM), and fetal bovine serum (FBS) were obtained from Invitrogen-Gibco (Grand Island,

\footnotetext{
* Corresponding author: e-mail: 907761215@qq.com

\# The author contributed equally to this work.
} 


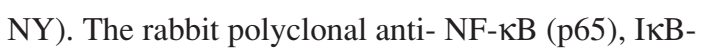
$\alpha, \mathrm{P}-\mathrm{I} \kappa \mathrm{B}-\alpha$ antibodies were purchased from Santa Cruz Biotechnology (Santa Cruz, CA, USA). Peroxidase-conjugated AffiniPure goat anti-mouse $\operatorname{IgG}(\mathrm{H}+\mathrm{L})$ and peroxidase-conjugated AffiniPure goat anti-rabbit $\operatorname{IgG}(\mathrm{H}+\mathrm{L})$ were purchased from PTG (Chicago, IL, USA).

\section{Experimental animals}

C57BL/6 male mice weighing 18-22 g were purchased from Jilin University Experimental Animal Center and acclimatized for 1 week before use. Rodent laboratory chow and tap water were provided ad libitum and maintained under controlled conditions with a temperature of $24 \pm 1^{\circ} \mathrm{C}$, humidity of $40-80 \%$, and a $12-\mathrm{h}$ light/12-h dark cycle. All of the experiments were approved by the Animal Use Committee of Jilin University (license number: SYXK (Ji) 2014-0006), in accordance with International Guiding Principles for Biomedical Research Involving Animals.

\section{Murine model of LPS-induced endotoxemia}

C57BL/6 mice were challenged in groups of four with LPS (dose range: $10-40 \mathrm{mg} / \mathrm{kg}$ ) by ip. Mice were observed on mortality for 6 days and twice a day. The items include feeding, activity, and grooming (smooth and shiny coats vs dull and ruffled coats). Using the LPS concentration that induced $80-90 \%$ lethal as working solution in the next step. In drug testing, using our established dose of LPS that was 80-90\% lethal, the effect of dioscin $(5,10$ and $20 \mathrm{mg} / \mathrm{kg})$ on LPS-induced mortality was assessed by dosing intraperitoneal dioscin $1 \mathrm{~h}$ before LPS challenge. To further observe the effects of dioscin on endotoxemia, mice were administered dioscin $(20 \mathrm{mg} / \mathrm{kg})$ at 0,1 or $4 \mathrm{~h}$ after LPS challenge, respectively. Mice in control and LPS groups were only given vehicle or LPS (10).

\section{Cytokine assays in vivo}

Cytokine concentrations in vivo were measured in serum. Dioscin $(20 \mathrm{mg} / \mathrm{kg})$ was given with an intraperitoneal injection (ip). Control mice received an equal volume of vehicle instead of dioscin. One hour later, all mice received LPS (30 $\mathrm{mg} / \mathrm{kg}$ ) by intraperitoneal injection (ip). Serum was separated from clotted blood at $0,1,3,6$ and $12 \mathrm{~h}$ following administration of intraperitoneal LPS. Serum was stored at $-70^{\circ} \mathrm{C}$ and concentrations of cytokine TNF- $\alpha$, IL-1 $\beta$ and IL- 6 were measured by ELISA using commercially available reagents according to the manufacturer's instructions (11).

\section{Western blot analysis.}

Western blot detection of NF- $\kappa \mathrm{B}$ in lung tissues of mice. The lung tissues of mice were homogenized and separated by $12 \%$ polyacrylamide gel electrophoresis. Proteins were blotted onto a 0.45 $\mu \mathrm{m}$ polyvinylidene fluoride (PVDF) membrane. Rabbit anti-NF- $\kappa \mathrm{B}, \mathrm{I}-\kappa \mathrm{B}, \mathrm{P}-\mathrm{I} \kappa \mathrm{B}$ monoclonal antibody $(1: 1000)$ and rabbit anti- $\beta$-actin polyclonal

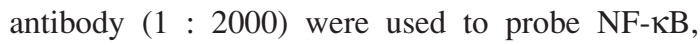
$\mathrm{I}-\kappa \mathrm{B}, \mathrm{P}-\mathrm{I} \kappa \mathrm{B}$ and $\beta$-actin in mice tissues. HRP-conjugated goat anti-rabbit IgG was used as secondary antibody at $1: 10000$ dilution. The density of recognized NF- $\kappa B$, I- $\kappa B$, P-I $\kappa B$ was compared to that of control $\beta$-actin and their ratio was used as a relative expression level of NF- $\kappa \mathrm{B}, \mathrm{I}-\kappa \mathrm{B}, \mathrm{P}-\mathrm{I} \kappa \mathrm{B}$ in injured mice tissues.

\section{Statistical analysis.}

All data were expressed as the mean \pm SD. Data analysis used SPSS version 18.0 (SPSS Inc., Chicago, IL, USA). Survival rates were estimated using the Kaplan-Meier method and a log-rank test. Statistical significance was accepted when $\mathrm{p}<0.05$ or $\mathrm{p}<0.01$.

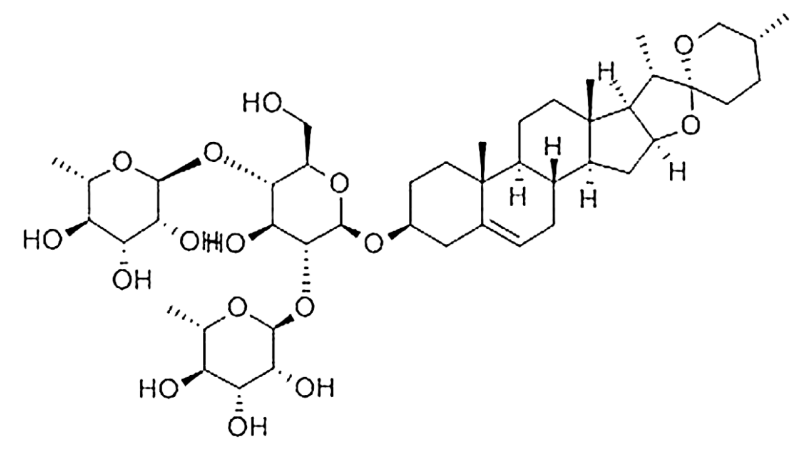

Figure 1. The structure of dioscin 
A

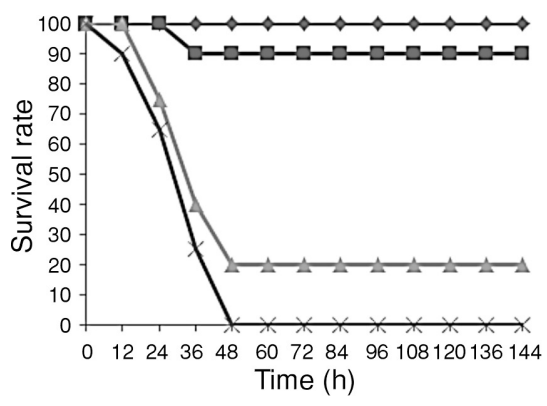

B

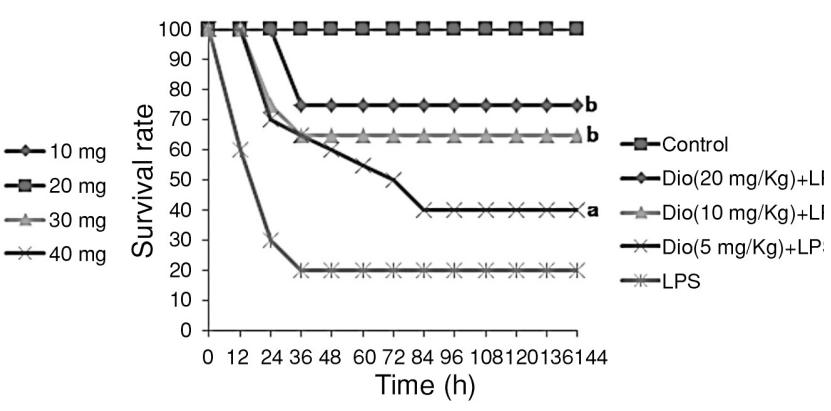

C

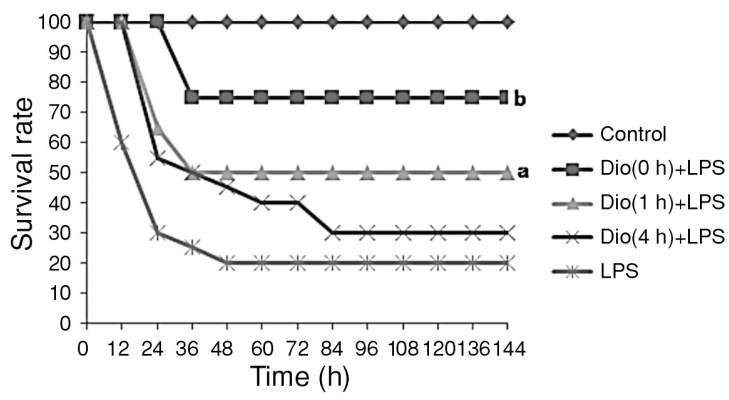

Figure 2. The survival rate of mice challenged with LPS of different doses and effect of single dose dioscin on survival of LPS challenged mice. A, The survival rate (\%) of mice challenged with LPS of different doses. Mice were given 10, 20, $30 \mathrm{or} 40 \mathrm{mg} / \mathrm{kg}$ of LPS by ip without treatment with dioscin ( $\mathrm{n}=12$ for each group). B, Effect of single dose dioscin (Dio) on survival of LPS-challenged mice before LPS injection. Mice were divided into control, LPS and florfenicol treatment groups ( $\mathrm{n}=12$ for each group). Mice in dioscin treatment group were treated orally with $5 \mathrm{mg} / \mathrm{kg}, 10 \mathrm{mg} / \mathrm{kg}$ and $20 \mathrm{mg} / \mathrm{kg}$ of dioscin $1 \mathrm{~h}$ before LPS challenge with $30 \mathrm{mg} / \mathrm{kg}$. Mice in control and LPS groups were only given vehicle or LPS. The survival was assessed every $12 \mathrm{~h}$ for 7 days throughout the experiment. C, Effect of single dose dioscin (Dio) on survival of LPS-induced mice after LPS injection. Mice were pretreated with $30 \mathrm{mg} / \mathrm{kg}$ of LPS, and then $10 \mathrm{mg} / \mathrm{kg}$ of dioscin was administered at 0,1,4 h after LPS injection, respectively. Mice in control and LPS groups were only given vehicle or LPS ( $\mathrm{n}=16$ for each group). The survival was monitored every $12 \mathrm{~h}$ for 6 days. ${ }^{\mathrm{a}} \mathrm{p}<0.05,{ }^{\mathrm{b}} \mathrm{p}<0.01$ vs LPS group. ${ }^{\mathrm{c}} \mathrm{p}<0.01 \mathrm{vs}$ control

\section{RESULTS}

\section{Effect of dioscin on LPS-mediated mortality}

First, we established the murine model of LPSinduced endotoxemia. In the present study, we chose $30 \mathrm{mg} / \mathrm{kg}$ of LPS as lethal dosage to induce endotoxemia in mice (Fig. 2A). In the effect of dioscin on cum survival of LPS-challenged mice, mice were ip dosed with different doses of dioscin and $1 \mathrm{~h}$ later challenged with LPS as shown in Figure 2B. In the group of mice given LPS alone, the survival rate was only $20 \%$ after $48 \mathrm{~h}$. In contrast, in the groups that received dioscin at doses of $5 \mathrm{mg} / \mathrm{kg}, 10 \mathrm{mg} / \mathrm{kg}$ or 20 $\mathrm{mg} / \mathrm{kg}$, survival rate were up to $40 \%, 65 \%$, and $70 \%$, respectively. The survival rate $(5,10,20 \mathrm{mg} / \mathrm{kg}$ groups) were significantly increased compared to that of the group that only received LPS $(\mathrm{p}<0.01$ or $0.05)$. Next, we examined the therapeutic effects of dioscin on LPS induced endotoxemia to investigate whether dioscin still protect mice from death. A single dose of dioscin $(20 \mathrm{mg} / \mathrm{kg})$ given at 0 or $1 \mathrm{~h}$ after
LPS challenge significantly increased survival rate of mice compared to LPS group ( $p<0.01$ or 0.05 ), and the survival rates were $75 \%$ and $50 \%$, respectively (Fig. 2C). There was no significant diference found in the group of drug administration at $4 \mathrm{~h}$ delayed. Taken together, these findings indicate that dioscin consistently protects mice from LPSinduced death.

\section{Effect of dioscin on cytokine responses in LPS- challenged mice}

To define the effects of dioscin on cytokine responses in vivo, we collected serum from mice at different time points after LPS injection, and determined cytokine concentrations with ELISA. As shown Figure 3, the cytokine concentrations in dioscin-pretreated were significantly different from those of LPS alone group at $1.3 \mathrm{~h}$ for TNF- $\alpha(\mathrm{p}<$ 0.01 or 0.05$)$, at $3 \mathrm{~h}$ for IL-6 $(\mathrm{p}<0.01)$ and at $12 \mathrm{~h}$ for IL-1 $\beta(p<0.05)$, Dioscin consistently and significantly reduced inflammatory cytokine productions. 
Further analysis of the samples collected at $24 \mathrm{~h}$ showed that the cytokine levels were either undetectable or close to baseline (data not shown).

\section{Effects of dioscin on LPS-induced NF-KB sig- naling pathway activation}

In this study, we examined the effect of dioscin on the LPS induced NF- $\mathrm{KB}$ activation in lung tissue by Western blotting analysis. As shown in figure 4,

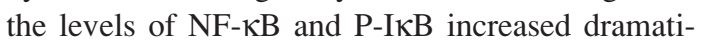
cally after $1 \mathrm{~h}$ of stimulation with LPS. But dioscin markedly inhibited LPS-induced activation of NF$\kappa \mathrm{B}$ and $\mathrm{P}-\mathrm{I} \kappa \mathrm{B}$ in a dose-dependent manner. The level of $\mathrm{I} \kappa \mathrm{B}$ showed an the opposite trend.

\section{DISCUSSION AND CONCLUSION}

Bacterial Sepsis is caused by endotoxin such as LPS produced by bacteria in the bloodstream. To prevent infection, animals and human have developed precise innate immunity against infection, which has been discovered recently. For example, it has been found that one of the Toll-like receptors (TLR) expressed on cell membrane recognizes LPS, transduces the insulting signal to nuclear, results in proinflammatory cytokine production, and eventually, modifies acquired immunity (11). Reduction of pro-inflammatory immune responses during endo- toxemia could improve survival. Based on this information, the pharmacological inhibition of these inflammatory mediators is an important target in the treatment of endotoxemia with a bacterial infection. In the study, we are exploring the mechanism of dioscin in inhibiting TNF- $\alpha$ and other proinflammatory cytokines production and investigating if dioscin uses a similar mechanism in intervening TLR pathway

In the experiment, we tested survival rate in a murine model of LPS-induced endotoxemia. As we expected, LPS-induced mortality was significantly reduced by prior to or after treatment with dioscin. And then we tested the levels of pro-inflammatory cytokines in murine serum. The data showed that the productions of TNF- $\alpha$, IL- 1 and IL- 6 were significantly decreased by dioscin. These observations showed that dioscin has anti-inflammatory activity in vivo and could relieve LPS-induced endotoxemia. NF- $\kappa \mathrm{B}$ pathway, which activated by TLR, plays important role in the secretion of pro-inflammatory cytokines in LPS-stimulated macrophages, such as TNF- $\alpha$, IL-6, and IL-1 $\beta$ (12). To further characterize the nature of the inhibitory effect of dioscin on cytokine production, we examined the effects of dioscin on the activation of the transcription factor $\mathrm{NF}-\mathrm{\kappa B}$ signaling pathways. Inhibition of the production of these signaling pathways may explain
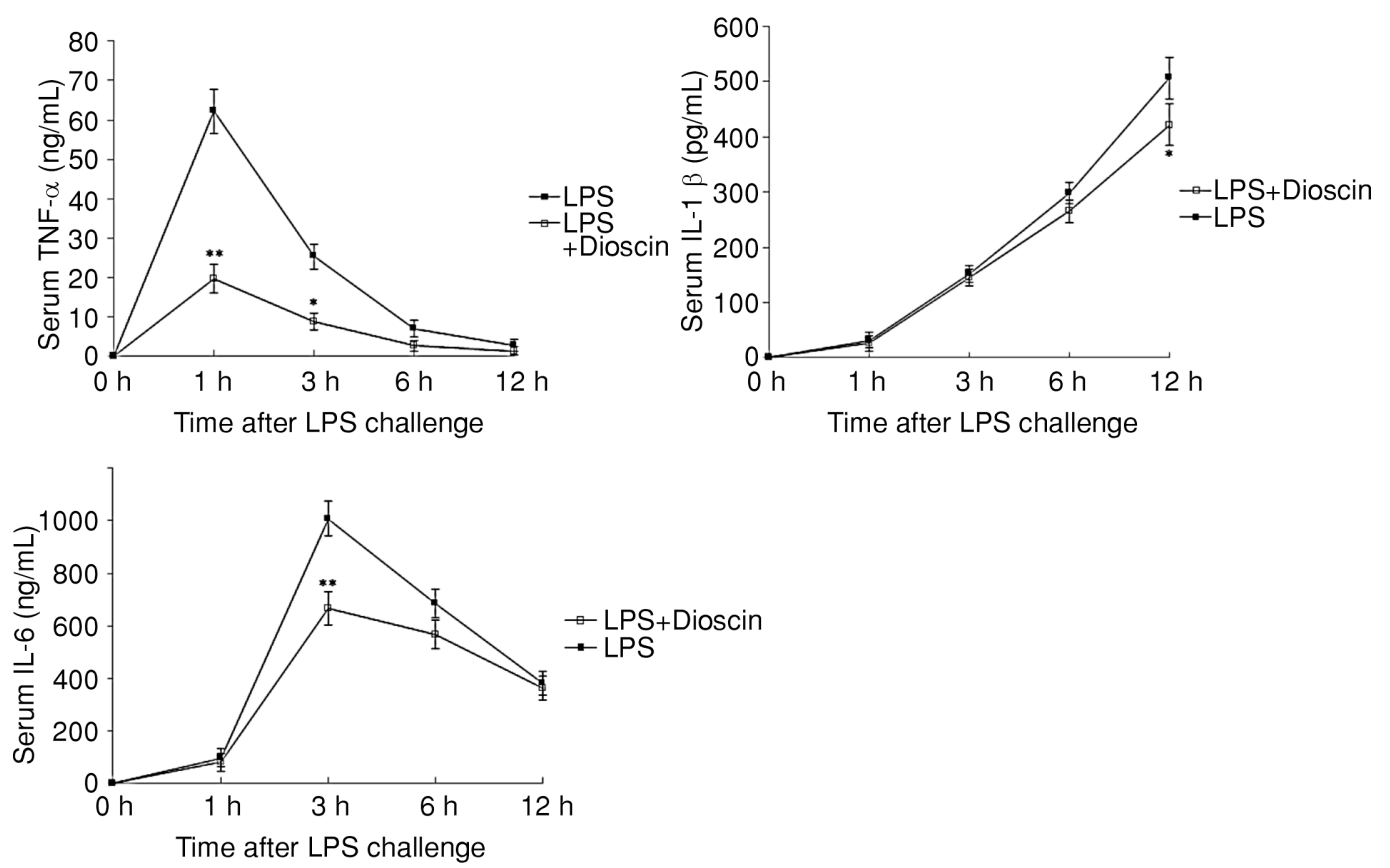

Figure 3. Effect of single-dose dioscin (Dio) on TNF, IL-1 3 , IL-6 induced by $30 \mathrm{mg} / \mathrm{kg} \mathrm{LPS}$. Mice were given dioscin (10 mg/kg) by ip $1 \mathrm{~h}$ before challenge with LPS. Serum levels of TNF, IL-1 $\beta$, IL-6 were measured at $0,1,3,6$ and $12 \mathrm{~h}$ following LPS challenge $(\mathrm{n}=16)$. Means \pm SD. $* \mathrm{p}<0.05, * * \mathrm{p}<0.01$ vs LPS 

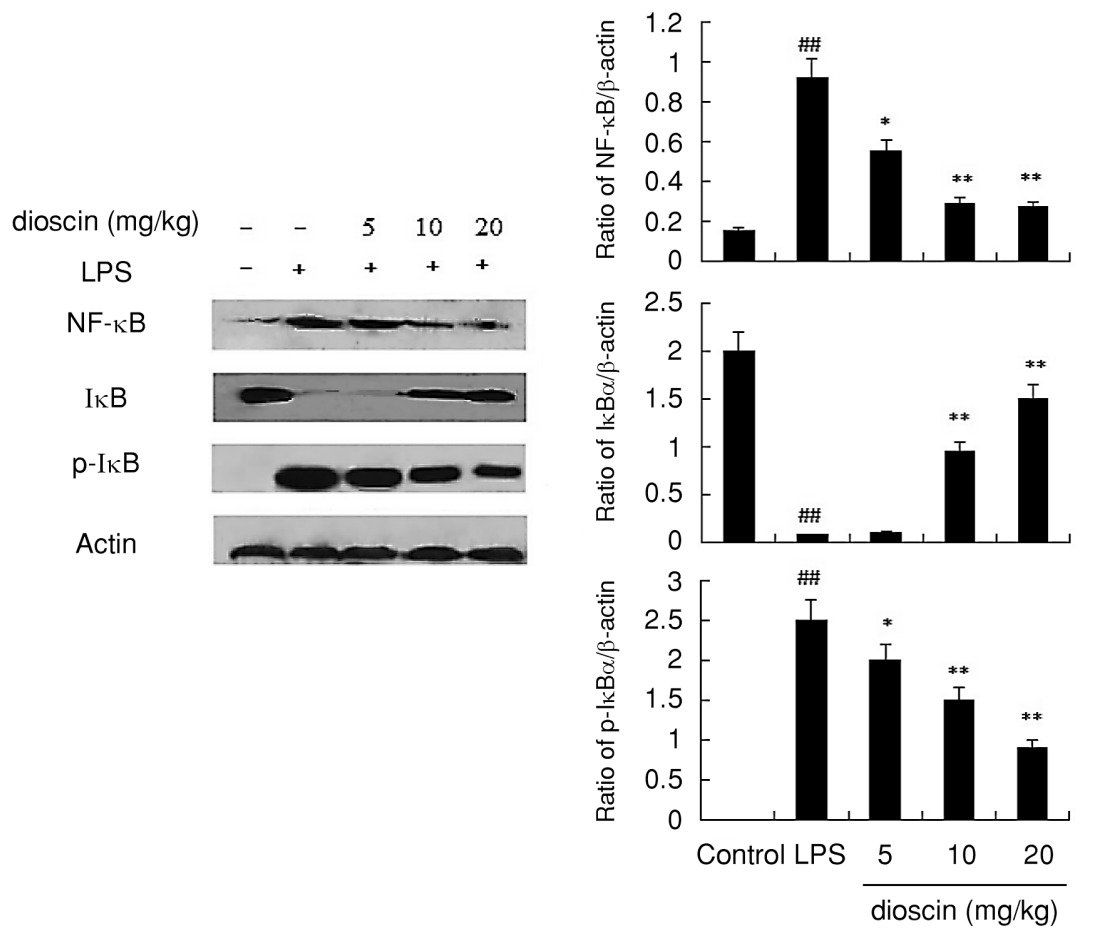

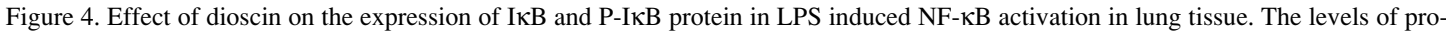

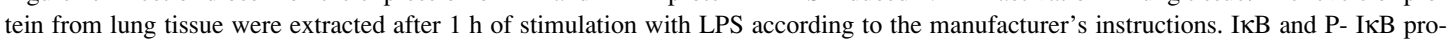
tein expression was tested by Western blot- analysis.*p $<0.05$ or $* * \mathrm{p}<0.01$ vs LPS group

the potent activity of dioscin as a suppressor of inflammatory cytokines. In unstimulated condition, $\mathrm{NF}-\kappa \mathrm{B}$ is localized to the cytosol due to its binding with IкB. However, when cells are activated by LPS, I $\mathrm{B}$ is phosphorylated by I $\mathrm{\kappa B}$ kinase and degraded, and then the released NF- $\kappa \mathrm{B}$ migrates into the nucleus and turns on transcription (13). Therefore, the activation of NF- $\kappa \mathrm{B}$ was assessed measuring the degree of phosphorylation of $\mathrm{I} \kappa \mathrm{B} \alpha$ protein, too.

In our study, we detected the expression of NF$\kappa \mathrm{B}, \mathrm{I} \kappa \mathrm{B} \alpha$ and $\mathrm{P}-\mathrm{I} \kappa \mathrm{B} \alpha$ in the lung tissues of mice with endotoxemia treated with or without dioscin to investigate whether dioscin protect major organ with endotoxemia by inhibiting NF- $\kappa \mathrm{B}$ expression. As shown in Figure 4, treatment with LPS resulted in phosphorylation of $\mathrm{I} \kappa \mathrm{B}$, then the combination of NF $\kappa B-I \kappa B$ untie, released NF- $\kappa B$ in cytosol. So the concentrations of NF- $\kappa \mathrm{B}$ and $\mathrm{p}-\mathrm{I} \kappa \mathrm{B} \alpha$ were increasement and activation, but concentration of I $\mathrm{K} B \alpha$ was decreasement. when we treated with different concentrations of dioscin, the activations of NF- $\kappa \mathrm{B}$ and $\mathrm{p}-\mathrm{I} \kappa \mathrm{B} \alpha$ were significantly blocked by dioscin in a dose-dependent manner. Meantime, the concentration of I $\mathrm{B}$ was increasement.
In conclusion, the data from the murine model of endotoxemia demonstrated that dioscin could inhibit LPS-induced pro-inflammatory cytokines TNF- $\alpha$, IL-6 and IL-1 $\beta$ production in vivo, and rescue mice from LPS-induced death by reducing the pro-inflammatory cytokines production. It improves survival in murine endotoxemia induced by LPS through preventing activation of NF- $\kappa B$ signaling pathways. Our findings suggest that the use of dioscin may provide a safe and effective treatment option for inflammation-mediated endotoxemia.

\section{REFERENCES}

1. Cheng Y., Hu X., Liu C., Chen M., Wang J. et al.: Cell Physiol. Biochem. 41, 205 (2017).

2. Karima R., Matsumoto S., Higashi H., Matsushima K.: Mol. Med. Today 5, 123 (1999).

3. Guan S., Feng H., Song B., Guo W., Xiong Y. et al.: Int. Immunopharmacol. 11, 2194 (2011).

4. Li H., Wang S., Zhan B., He W., Chu L. et al.: Parasit. Vectors 10, 222 (2017).

5. Kim M., Sung H., Hong K.: J. Pharmacopuncture 16, 007 (2013). 
6. Hsieh M., Tsai T., Hsieh Y., Wang C., Han L.: Arch. Toxicol. 87, 1927(2013).

7. Li H., Huang W., Wen Y., Gong G., Zhao Q., Yu G.: Fitoterapia 81, 1147(2010).

8. Zhao X., Cong X., Zheng L., Xu L., Yin L., Peng J.: Toxicol. Lett. 14, 69 (2012).

9. Yao H., Hu C., Yin L. et al.: Int. Immunopharmacol. 36, 132 (2016).

10. Zhang X., Song Y., Ci X., An N., Fan J. et al.: Int. Immunopharmacol. 8, 982 (2008).
11. Zhang X., Song Y., Ci X. et al.: Int. Immunopharmacol. 8, 179 (2016).

12. Lu J., Huang G.., Wang Z. et al.: Food and Chem. Toxicol. 62, 172 (2013).

13. Bae E-A., Trinh H-T., Jang Y-A., Yun H-K. Hong S-S. et al.: Food Agricul. Immunol. 20, 155 (2009).

Received: 28. 12. 2017 